\title{
The Leachate Release and Microstructure of the Sewage Sludge under the Anaerobic Fermentation
}

\author{
Yiqie Dong, Haijun Lu, Jixiang Li, and Changhong Wang \\ Institute of Porous Mechanics, Wuhan Polytechnic University, Wuhan 430023, China \\ Correspondence should be addressed to Haijun Lu; lhj_whpu@163.com
}

Received 1 February 2015; Accepted 21 April 2015

Academic Editor: Yuangen Yang

Copyright (C) 2015 Yiqie Dong et al. This is an open access article distributed under the Creative Commons Attribution License, which permits unrestricted use, distribution, and reproduction in any medium, provided the original work is properly cited.

Pollutant release, pore structure, and thermal effect of sewage sludge during anaerobic fermentation were investigated. Results showed that the $\mathrm{pH}$ value firstly declined and then increased during anaerobic fermentation. The $\mathrm{BOD}_{5}$ and organics of sewage sludge declined, and the $\mathrm{BOD}_{5}$ of samples which was originally neutral declined as much as $53.6 \%$. The micropore of samples was relatively developed. The biggest adsorption amount was $69.2 \mathrm{~cm}^{3} / \mathrm{g}$. The average pore size was enlarged about $16.0-19.8 \%$ under anaerobic fermentation. There existed endothermic valley during heating procedure of $0-200^{\circ} \mathrm{C}$ because of the dehydration, and the mass loss was $60.9-72.5 \%$. The endothermic valley of the sample fluctuated at the 14th day in the anaerobic fermentation. During the heating procedure of $200-600^{\circ} \mathrm{C}$, there existed exothermal peaks because of the oxidation and burning of the organics. The curve of sample which was originally neutral had comparatively large endothermic valley and exothermal peak.

\section{Introduction}

As a kind of byproduct produced in the treatment of the municipal wastewater, the sewage sludge has properties such as high moisture content, perishability, instability, and putrid odor. The environmental problem caused by the sewage sludge is also one of the most highlighted ones at present and in the future [1]. According to relative researches, the amount of the sewage sludge produced in the whole nation was $2.241 \times$ $10^{7} \mathrm{t}$ in a year, and half of it has not been harmlessly treated, causing the pollution of air, soil, and water [2].

Nowadays, the treatments of sewage sludge were mainly sanitary landfill and incineration [3-5]. However, due to the properties such as the high moisture content, polluting, and bad engineering properties of the sewage sludge, those treatments mentioned above were limited to sufficiently treat the sewage sludge $[6,7]$. Thus, the method-the anaerobic fermentation of the sewage sludge-was widely applied in the treatment of sewage sludge and also attached great importance from scholars all over the world [8]. In this method, most of the organics in the sewage sludge were transformed into useful energy by the anaerobic fermentation of microorganism. Furthermore, plenty of nitrogen, phosphate, potassium could be separated from the leachate produced in this fermentation, making the recycling of sewage sludge much easier. This method could also help stabilize and decrease the amount of sewage sludge and make it harmless [9]. As for the procedure of anaerobic fermentation at present, what many researchers focused on was the releasing of nitrogen and phosphorus. However, the researches on influence of $\mathrm{pH}$ value on the efficiency of the anaerobic fermentation and the changing rules of the microstructure of sewage sludge were much less [10].

In this page, the effect of the original $\mathrm{pH}$ value on the efficiency of the anaerobic fermentation was determined by analyzing the pore structure and the thermal effect in the anaerobic fermentation. The $\mathrm{pH}$ value, organic content, and $\mathrm{BOD}_{5}$ of samples with differently original $\mathrm{pH}$ value were determined by pollutant releasing test; the change of pore structure in the anaerobic fermentation was determined by static nitrogen adsorption test. The component and phase deformation rules in the process were determined by TGDTA test.

\section{Materials and Methods}

2.1. Testing Materials. In order to observe the influence of differently original $\mathrm{pH}$ value of samples on the releasing 
TABLE 1: The physical properties of samples.

\begin{tabular}{lccc}
\hline Pollutant & Sample I & Sample II & Sample III \\
\hline Proportion $(\mathrm{mg} / \mathrm{L})$ & 1.24 & 1.24 & 1.27 \\
Organics $(\%)$ & 46.6 & 43.2 & 41.8 \\
Moisture content $(\mathrm{mg} / \mathrm{L})$ & 69.7 & 80.3 & 78.4 \\
Pore ratio & 3.17 & 3.36 & 3.50 \\
Permeability coefficient $(\mathrm{cm} / \mathrm{s})$ & $1.44 \times 10^{-8}$ & $1.20 \times 10^{-8}$ & $1.07 \times 10^{-8}$ \\
Compressive strength $\left(\mathrm{kg} / \mathrm{cm}^{2}\right)$ & 0.059 & 0.068 & 0.066 \\
BOD $_{5}(\mathrm{mg} / \mathrm{L})$ & 238 & 194 & 190 \\
$\mathrm{COD}(\mathrm{mg} / \mathrm{L})$ & 618 & 555 & 584 \\
\hline
\end{tabular}

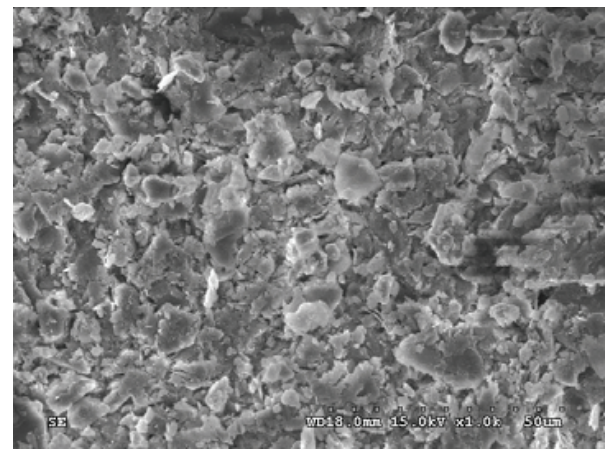

FIGURE 1: The microstructure of original sewage sludge.

rules of sewage sludge leachate and its microstructure, the samples used in the tests were separately taken from the Tangxun Lake wastewater treatment plant (as sample I), the Hanxi wastewater treatment plant (as sample II), and the Sha Lake wastewater treatment plant (as sample III). Since the sewage sludge was influenced by factors such as the numbers of the light industry enterprises and the numbers of residents around the plant and the original moisture content, the testing of samples' $\mathrm{pH}$ values strictly followed the Chinese standard: water quality-determination of $\mathrm{pH}$ valueglass electrode method (GB/T 6920-86). And the original $\mathrm{pH}$ values of samples were $5.89,6.96$, and 8.13 which were named as sample I, sample II, and sample III, respectively. The physical properties of sewage sludge were shown in Table 1.

Since the scanning electron microscope (SEM) pictures and the curves of pore volume-pore size of three kinds of samples were similar, the SEM pictures and curves of sample II were chosen as model for analyzing. The SEM pictures of sample II were shown in Figure 1, and curve of pore volume-pore size was shown in Figure 2. From the picture and curve, it is shown that the samples were made up of many microtablets, and connection between those tablets was strong and the pore was relatively small. The distribution of the pore volume was relatively uniform, and the maximum value of the pore volume was $0.157 \mathrm{~cm}^{3} / \mathrm{g}$. The proportion of pores between 2 and $4 \mathrm{~nm}$ was relatively large.

2.2. Testing Methods. Before the tests, a small hole was made on the upper end of the conical robber plug, and the anticontaminating rubber tubing was inserted into that hole,

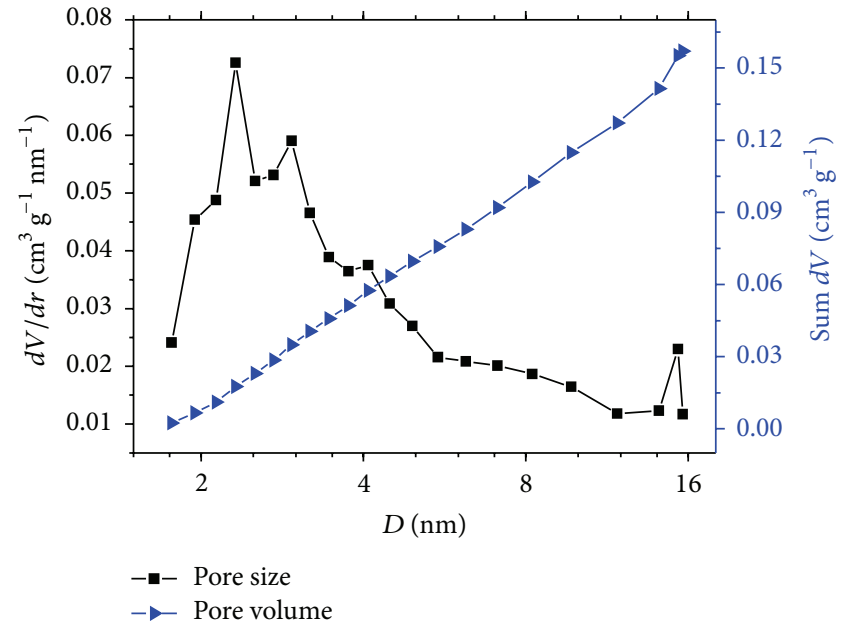

FIGURE 2: The curve of pore-volume and pore size of original sewage sludge.

making it strongly connected with each other. Then, the big sundries in the sewage sludge were removed manually. In the test, sewage sludge with differently original $\mathrm{pH}$ values was separately put into the $500 \mathrm{~mL}$ conical flasks. In every flask, the weight of the sewage sludge samples was all $240 \mathrm{~g}$. Then Vaseline was brushed on the bottleneck of the conical flasks, and the flasks were sealed by the rubber plugs prepared before. The other end of the rubber tubing in the plug was put in a container containing distilled water, ensuring that the conical flask was under anaerobic and airtight condition. After that, the conical flasks were kept in thermostatic water bath box (Jintan Chenghui Instrument Factory), controlling the temperature at $95^{\circ} \mathrm{C}$ to improve the efficiency of the anaerobic fermentation of the sewage sludge [11].

The conical flasks were taken out and put into a container with oxygen at the 2 th, 7 th, 10th, 14th, 17th, 21th, and 28th day after the beginning of the anaerobic fermentation, respectively. When the flasks were taken out, a little of the sewage sludge was taken out and a filter screen was put on the bottleneck of the flask. Then, the leachate in the flask was poured into a small beaker. Then the flasks were sealed again and put back into the water bath box.

2.2.1. Pollutant Releasing Test. The $\mathrm{pH}$ value and the organic content of the sewage sludge and the relationship between 
the $\mathrm{pH}$ value, organic content, and the time of the anaerobic fermentation were tested according to determination method for municipal sludge in wastewater treatment plant (CJ/T 221-2005). According to water quality-determination of biochemical oxygen demand after 5 days $\left(\mathrm{BOD}_{5}\right)$ for dilution and seeding method (HJ 505-2009) and water quality-determination of the chemical oxygen demand-fast digestion-spectrophotometric method (HJ/T 399-2007), the $\mathrm{BOD}_{5}$ and $\mathrm{COD}$ of the leachate from the samples were determined and the relationship between them and the time of anaerobic fermentation was analyzed.

2.2.2. Static Nitrogen Adsorption Test. The properties of pore structure of the sewage sludge with differently original $\mathrm{pH}$ value at the 14 th and 28th days in the anaerobic fermentation were determined by the static nitrogen test, using the JWBK static nitrogen adsorption instrument (Beijing JWGB Sci.\&Tech. Co., Ltd.). In the test, the temperature was the saturation temperature of the liquid nitrogen, and nitrogen (99.9\%) was used as the adsorbing medium. The relative pressure ratio of $P / P_{0}$ (in low temperature nitrogen adsorption, $P$ was the equilibrium pressure and $P_{0}$ was the saturation pressure) was between 0.01 and 0.995 . Under the condition mentioned above, 22 points of the ratio of $P / P_{0}$ were chosen to have isotherm adsorption and desorption. The distribution of pore size and pore volume in the test was determined by the standard BET method [12].

2.2.3. TG-DTA Test. In the tests, three kinds of samples were, respectively, taken out at 14 th and 28th days in the anaerobic fermentation. To test the thermogravimetry (TG) and the differential thermal tnalysis (DTA) of those samples, the TG-DTA simultaneous thermal analyzer (Beijing Henven Scientific Instrument Factory) was applied to the test to analyze the result of the samples and the phase deformation. The range of the temperature of the analyzer was $0-1000^{\circ} \mathrm{C}$ and the hearting rate of it was controlled at $10^{\circ} \mathrm{C} / \mathrm{min}$.

\section{Results and Discussions}

3.1. Releasing Rules of the Leachate. The changing relationship between the $\mathrm{pH}$ value, the organic content, and the time of the anaerobic fermentation was shown in Figure 3. From the figure, it can be drawn that the curve of the $\mathrm{pH}$ value along with the time was a concave curve. In the curve, the $\mathrm{pH}$ values of samples I, II, and III declined to 5.61, 6.61, and 7.74, respectively, at the 7 th day of the anaerobic fermentation of the sewage sludge. When the test was at the end, the changes of $\mathrm{pH}$ values of samples I and III were gradually stable, the difference value between the original $\mathrm{pH}$ value and the final $\mathrm{pH}$ value was relatively small. However, the final $\mathrm{pH}$ value of sample II increased $4.50-7.27 \%$ compared with the original value. From Figure 4, it is shown that the organic content of samples gradually declined with the continual of the fermentation, and the decreasing was fast at the beginning of the anaerobic fermentation. After 28 days, the organic content decreased $27.5-37.3 \%$ compared with the original content.

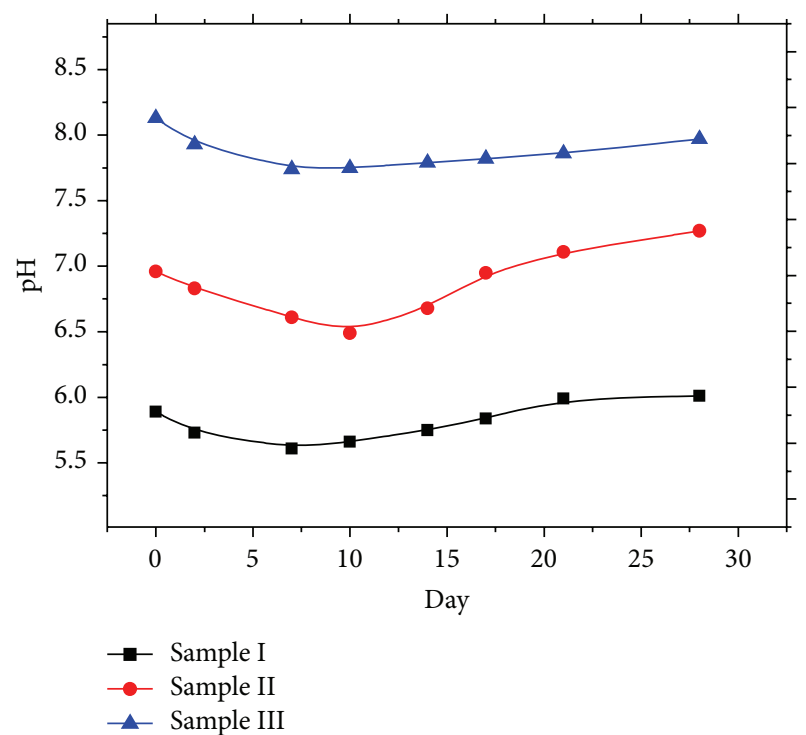

Figure 3: The curve of $\mathrm{pH}$ value.

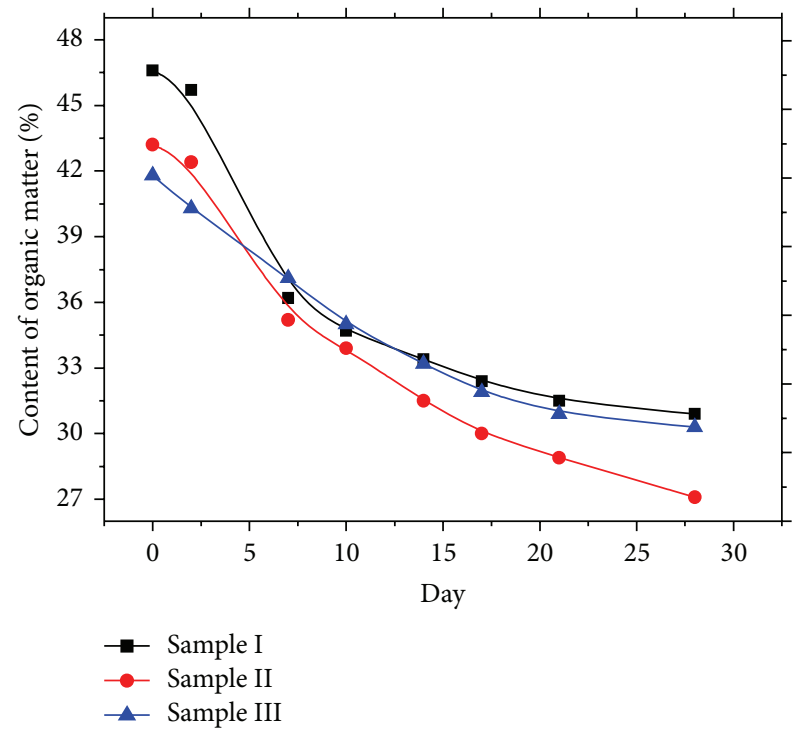

FIGURE 4: The curve of organic matter.

The decreasing rates of samples I and III were gradually stable, while sample II was still slowly decreasing.

At the beginning, under the coaction of the organics and the acidogenic bacteria, the protein and part of the insoluble organics in the samples were transformed to water soluble matter, such as monosaccharide amino, lower fatty acid, by the ectoenzyme released by the bacteria. Then, the water soluble matter produced above was transformed to plenty of carbon dioxide $\left(\mathrm{CO}_{2}\right)$, acetic acid $\left(\mathrm{CH}_{3} \mathrm{COOH}\right)$, and energy by the endoenzyme, making the acidity of leachate stronger. Thus, the $\mathrm{pH}$ value of the samples began to decrease and the organic content also rapidly declined at the start of the fermentation. With the continual of the anaerobic fermentation and the action of methanogens, the organic acid was resolved and methane was released. In this procedure, 


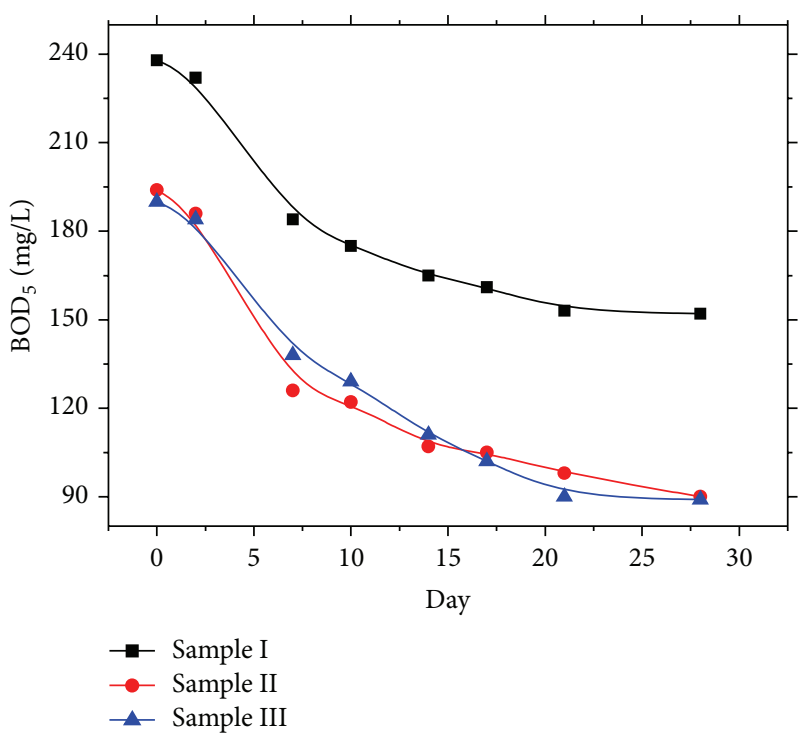

Figure 5: The curve of $\mathrm{BOD}_{5}$ of sewage sludge.

it was easy for the organic acid to combine with the various forms of nitrogen (such as $\mathrm{NH}_{4}{ }^{+}, \mathrm{NO}_{3}{ }^{-}$) in the sewage sludge, and a small amount of ammonia gas $\left(\mathrm{NH}_{3}\right)$ was released, accelerating the increasing of $\mathrm{pH}$ value of the leachate $[13,14]$. Researches have shown that the suitable $\mathrm{pH}$ value for the living of methanogens was $6.80-7.20$. When the $\mathrm{pH}$ values were smaller than 6.00 or bigger than 8.00 , the adaptive capacity of methanogens was comparatively lower. Thus, the activity of methanogens in sample II was comparatively higher, resulting in the more significant increasing rate of $\mathrm{pH}$ value compared with samples I and III [15].

The changing relationship between $\mathrm{BOD}_{5}$ and the time of the anaerobic fermentation was shown in Figure 5. From the figure, it can be drawn that, in the fermentation of sewage sludge, the microorganism could significantly digest the organics in the sewage sludge. In detail, at the beginning of the fermentation, since there was no nitrogen imported in at such a closed environment, the aerobes could not live after the remaining oxygen in the container was consumed, resulting in the great decreasing of the number of the aerobes. Meanwhile, the activity of anaerobes, such as the acidogenic bacteria, gradually became stronger and they could effectively digest plenty of the biodegradable organics, leading to the low increasing speed of the $\mathrm{BOD}_{5}$ at the beginning of the fermentation and the rapid increasing rate after 2 days of anaerobic fermentation. When the experiment was completed, the decreasing range of the $\mathrm{BOD}_{5}$ of the samples was $36.1-53.6 \%$ compared with the original ones.

With the continual of the anaerobic fermentation, the insoluble organics in the sewage sludge were also resolved to mass of soluble organics (such as $\mathrm{CH}_{3} \mathrm{COOH}$ ) in the allogenic water, making the second digestion of the microorganism more difficult. Thus, degrading rate was greatly influenced by the outside factors ultimately. When the living environment was not suitable for the microorganism, the breeding and multiplying abilities of them were relatively weaker, influencing the degradation efficiency of the $\mathrm{BOD}_{5}$ in the leachate.

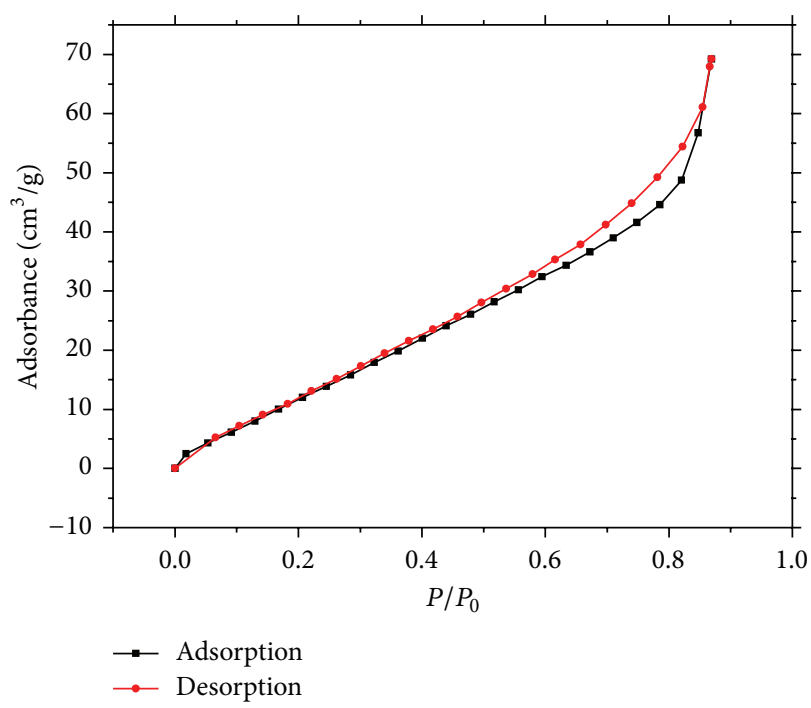

FIGURE 6: The adsorption-desorption isotherms of sample II.

3.2. Pore Structure. Since the adsorption-desorption isotherms of the different samples in the anaerobic fermentation were similar, the adsorption-desorption isotherms of sample II at the 14th day of the fermentation were chosen as model for analysis. From Figure 6, it is shown that the isotherm belonged to IV kinds according to the IUPAC classification method. From the isotherms, it can be seen that when the ratio of $P / P_{0}$ was small, there was embossing on the curve which was mainly caused by the adsorption of nitrogen that happened on the outside pore wall of the sewage sludge particles. Then, the amount of adsorption linearly increased with the ratio of $P / P_{0}$. When the ratio of $P / P_{0}$ increased to 0.3 , the adsorption isotherm and desorption isotherm began to separate and the procedure of desorption fell behind that of the adsorption; thus, there appeared a hysteresis loop of $\mathrm{H}_{3}$ kind. This phenomenon happened because the adsorption of the outside wall of the sewage sludge particles had reached saturation and the pores were gradually filled with nitrogen, leading to the start of the adsorption on the inside pore wall of the particles.

Since the inside of the pore was rough and the pores were bottleneck like, it was easier to adsorb nitrogen and form obstacles at the top of the pore to help stop the fast releasing of nitrogen gas in the desorption procedure. When the ratio of $P / P_{0}$ was larger than 0.6 , the adsorption happened on the inside wall of pore and gradually became saturated; thus, the adsorption in cavity of pore started. Because the cavity of pore was relatively large and could house large adsorption amount, the adsorption amount in this period and the area of the hysteresis loop both significantly increased. The maximum adsorption amount was as large as $69.24 \mathrm{~cm}^{3} / \mathrm{g}$.

The distribution curves of pore volume-pore size of samples I, II, and III were given in Figures 7-9. The average pore size of samples I, II, and III were shown in Table 2. According to the standard published by the IUPAC, pores can be divided into three kinds according to their pore size. Macropore was larger than $50 \mathrm{~nm}$, and mesopore was 


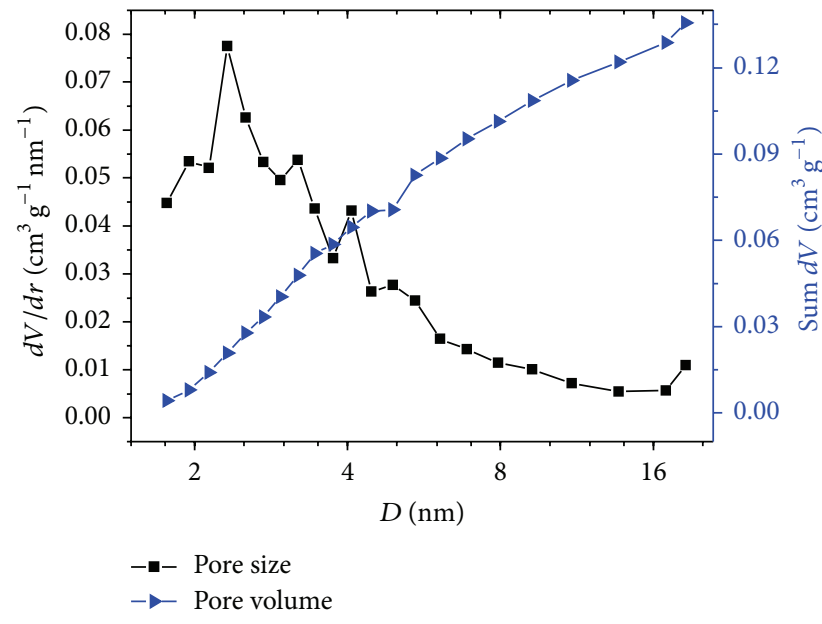

(a) 14th day of the anaerobic fermentation

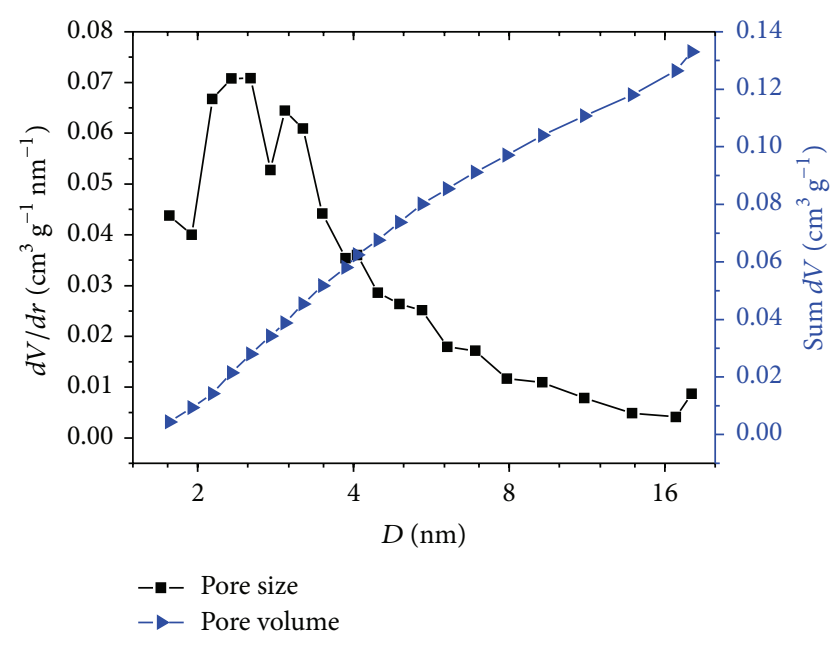

(b) 28th day of the anaerobic fermentation

FIgURE 7: The distribution curve of pore volume and pore size of sample I.

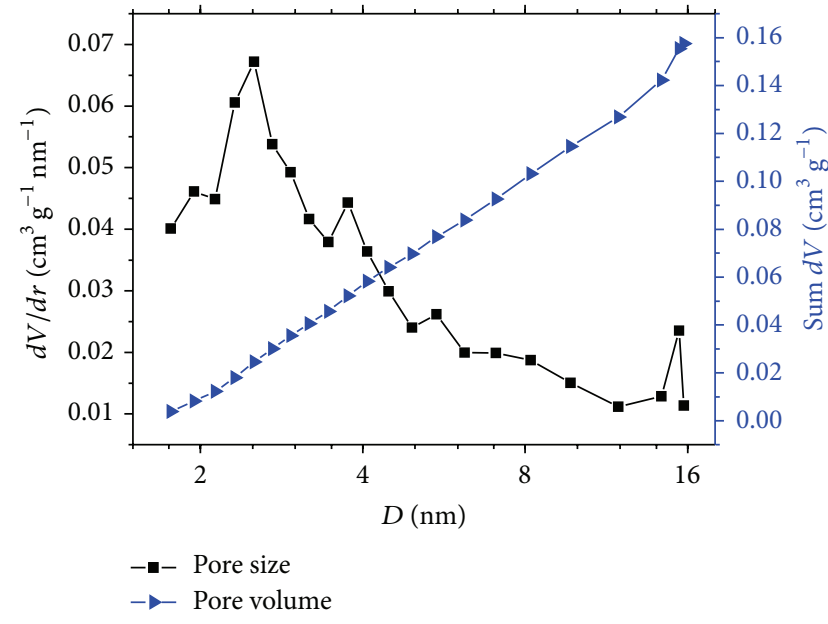

(a) 14th day of the anaerobic fermentation

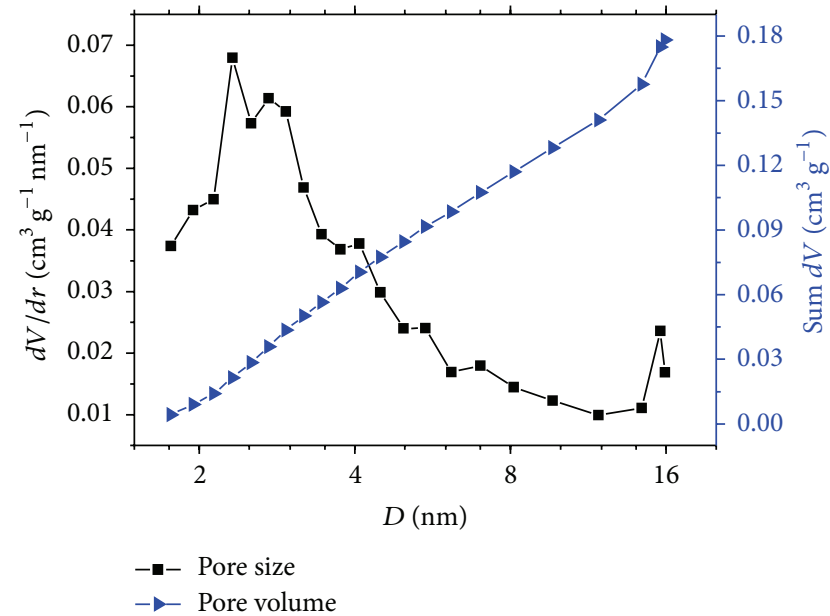

(b) 28th day of the anaerobic fermentation

FIGURE 8: The distribution curve of pore volume and pore size of sample II.

between 2 and $50 \mathrm{~nm}$, and the micropore was smaller than $2 \mathrm{~nm}$ [16]. From the Figures 7-9, it can be drawn that, after the anaerobic fermentation, the proportion of micropore was relatively large when the sewage sludge particles were smaller than $6 \mathrm{~nm}$. The proportion slightly increased when the pore size was larger than $14 \mathrm{~nm}$. The curve of pore volume was similar to a line; the maximum pore volume of three kinds of samples was similar, ranging from 0.126 to $0.178 \mathrm{~cm}^{3} / \mathrm{g}$.

Compared with the pore size of samples at the 14th day of the anaerobic fermentation, the average pore size of samples at the 28th day increased about $13.3-16.7 \%$, and the maximum values of pore volume of the sample at 14 th and 28 th days both had slight increase. The reason behind this was that, at the beginning of the anaerobic fermentation, the sewage sludge was mainly made up of a lot of organics macromolecule compounds. When the pore was formed, the outside and inside walls of pore were both rough. The microorganism parasitized in the allogenic water contained in the pores. With the lasting fermentation and the continual flow of the water in the pores, the degradable organics inside the pores and on the surface of the sewage sludge particles were consumed by the microorganism. The microorganisms nourished themselves and multiplied by this way, leading to the decreasing of $\mathrm{BOD}_{5}$ and smoothing the surface of the pore. Thus, at the 28th day of the fermentation, the specific surface areas of three kinds of samples were all smaller than that of the 14th day. The pore volume and the average pore size at the 28 th day were both increased compared with those of the 14th day.

The rule of the distribution of the pore volume-pore size was closely related to the environment condition of the anaerobic fermentation. When the experiment was completed, the total pore volume of sample II was $0.178 \mathrm{~cm}^{3} / \mathrm{g}$ increasing by $33.8 \%$ and $10.6 \%$, respectively, when compared with samples I and III. Meanwhile, the average pore size of sample II in 


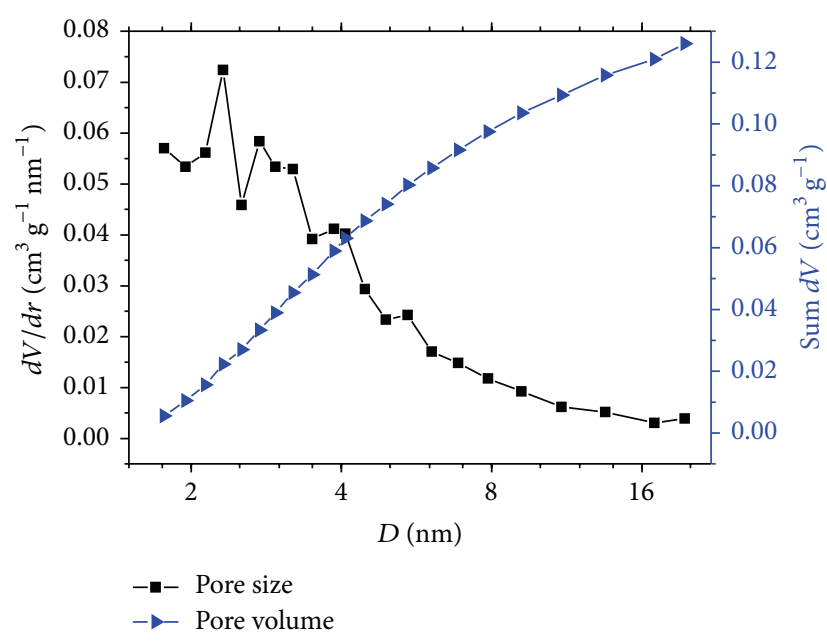

(a) 14th day of the anaerobic fermentation

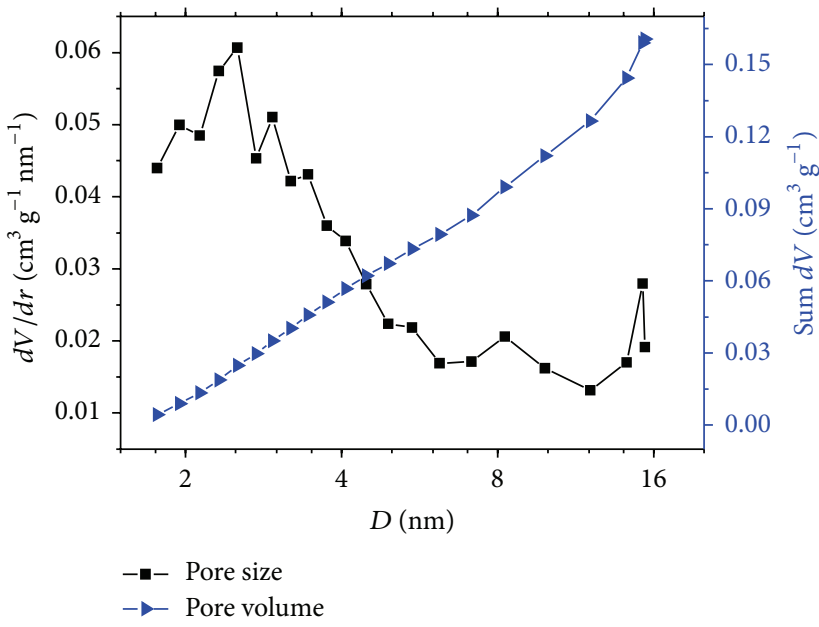

(b) 28th day of the anaerobic fermentation

FIGURE 9: The distribution curve of pore volume and pore size of sample III.

TABLE 2: The average pore size and specific surface area of samples.

\begin{tabular}{lccccrr}
\hline \multirow{2}{*}{ Days of anaerobic fermentation } & \multicolumn{2}{c}{ Sample I } & \multicolumn{2}{c}{ Sample II } & \multicolumn{2}{c}{ Sample III } \\
& 14 & 28 & 14 & 28 & 14 & 28 \\
\hline Average pore size $(\mathrm{nm})$ & 7.14 & 8.28 & 8.65 & 10.1 & 8.09 & 8.69 \\
Specific surface area $\left(\mathrm{m}^{2} / \mathrm{g}\right)$ & 76.0 & 72.8 & 64.3 & 59.5 & 73.9 \\
\hline
\end{tabular}

the fermentation was also larger than that of samples I and III. The specific surface area of sample II was smaller, indicating that the living environment of sample II was more acidic, which led to the weakening of the activity of methanogens at the end of the fermentation. Thus, during this period, the ability of methanogens to consume organics was weakened, resulting in much organic remaining on the pore walls of sewage sludge particles at the end of the test. Because of that, the total pore volume and average pore size were small, and the specific surface area was large.

3.3. Thermal Effect. The rules of the thermal effect at 14th, 28th day of the anaerobic fermentation were shown in Figures 10 and 11. And the mass loss of the samples under difference heating temperature was given in Table 3. Referring to the Handbook of Analytical Chemistry (thermal analysis), the change of the thermal effect that happened in any physical or chemical change would lead to the decreasing of the TG curve, the endothermic valley, and the exothermal peak of the DTA curve.

From Figures 10 and 11, it shown that the mass loss of each sample ranged from 60.9 to $72.5 \%$, forming more than $85 \%$ of the total mass loss when the heating temperature was between $0^{\circ} \mathrm{C}$ and $200^{\circ} \mathrm{C}$. This happened because the sewage sludge still contained much moisture when taken out from the treatment plant, even if it was mechanically dehydrated. Thus, mass of the free water and the weakbounded water in the sewage sludge particles was removed at this temperature, and there existed an endothermic valley on the curve. When the temperature was increased to 200$600^{\circ} \mathrm{C}$, the mass loss was $7-13 \%$, which was mainly caused by the burning of the organics and microorganism in the sewage sludge. And there appeared an exothermal peak when the temperature was $300^{\circ} \mathrm{C}$. Meanwhile, the microorganism died in the high temperature caused by the heat produced in the oxidative cleavage of the organics and microorganism. When the temperature was at $480^{\circ} \mathrm{C}$, since the combustible organics met the burning condition and produced much heat, the exothermal peak was more significant. Furthermore, when temperature was higher than $600^{\circ} \mathrm{C}$, the TG and DTA curves were both gradually stabilized, and there was no more severe endothermic or exothermal reaction. In this period, the content of the organics in the sewage sludge was very low and the arrangement and the component of the particles had been changed. At the time, there only existed a little amount of ash of the mental oxide which had high melting point and the strong-bounded water which have not been removed from the particles in the heating procedure.

From the TG curve of the samples at the 14th day of the anaerobic fermentation, it is shown that the obvious fluctuation happened at the endothermic valley at $100-200^{\circ} \mathrm{C}$, and it disappeared at the 28th day of the fermentation. Since the microorganism had relatively high activity at the 14th day, the reaction of resolving the organics was more severe. According to the analysis of the pore structure, there existed a little free water in the pore and the hole of the pore was small. When the temperature became higher, the heat conductivity of the wall of the pore differed from outside to the inside. Therefore, the temperature of the inside wall 
TABLE 3: The percentage of quality loss.

\begin{tabular}{|c|c|c|c|c|c|c|}
\hline \multirow{2}{*}{ Days of anaerobic fermentation } & \multicolumn{2}{|c|}{ Sample I } & \multicolumn{2}{|c|}{ Sample II } & \multicolumn{2}{|c|}{ Sample III } \\
\hline & 14 & 28 & 14 & 28 & 14 & 28 \\
\hline$<200^{\circ} \mathrm{C}$ & $61.9 \%$ & $66.8 \%$ & $67.0 \%$ & $72.5 \%$ & $60.9 \%$ & $70.1 \%$ \\
\hline $200-600^{\circ} \mathrm{C}$ & $8.48 \%$ & $7.70 \%$ & $9.20 \%$ & $12.7 \%$ & $7.33 \%$ & $9.31 \%$ \\
\hline$>600^{\circ} \mathrm{C}$ & $0.130 \%$ & $0.200 \%$ & $0.0600 \%$ & $0.390 \%$ & $0.680 \%$ & $0.150 \%$ \\
\hline Total mass loss & $70.5 \%$ & $74.7 \%$ & $76.3 \%$ & $85.5 \%$ & $69.0 \%$ & $79.5 \%$ \\
\hline
\end{tabular}

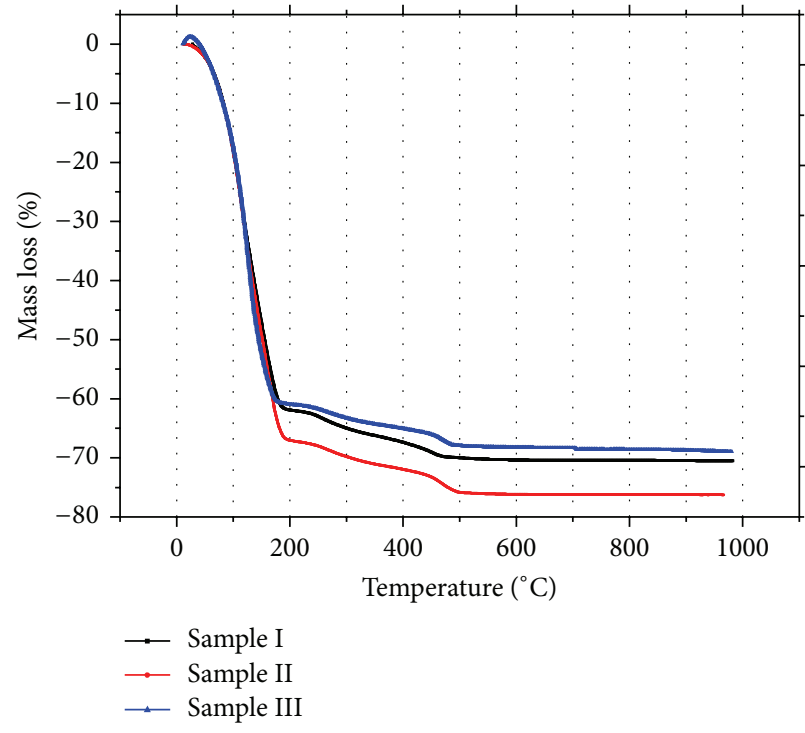

(a) The curve of TG

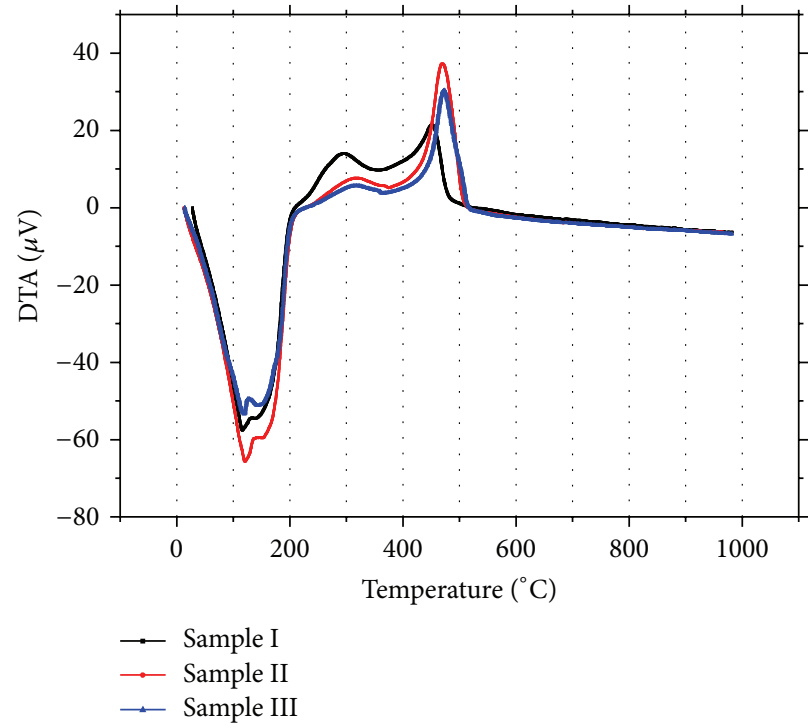

(b) The curve of DTA

FIGURE 10: The curve of the thermal effect at 14th day of the fermentation.

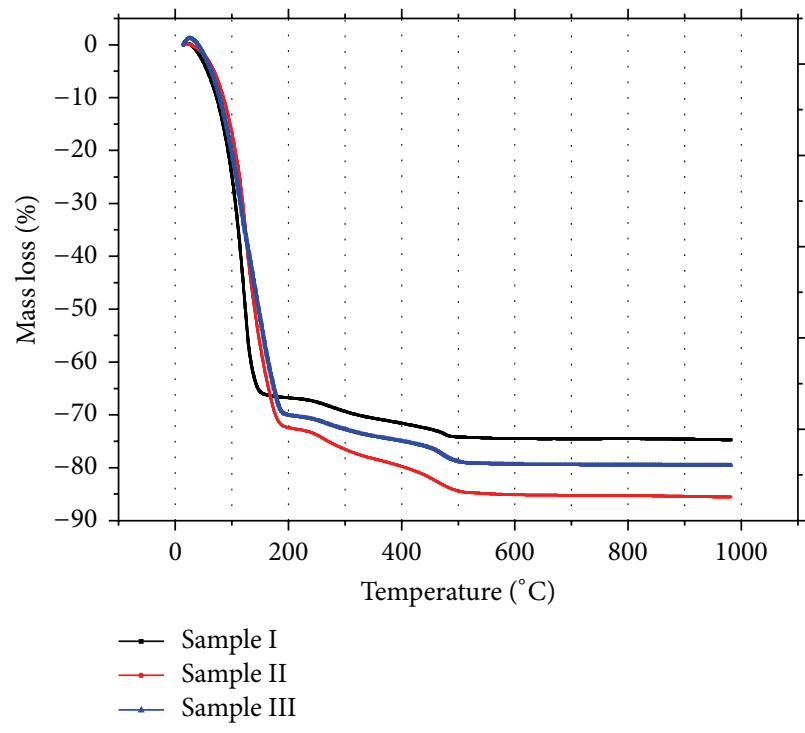

(a) The curve of TG

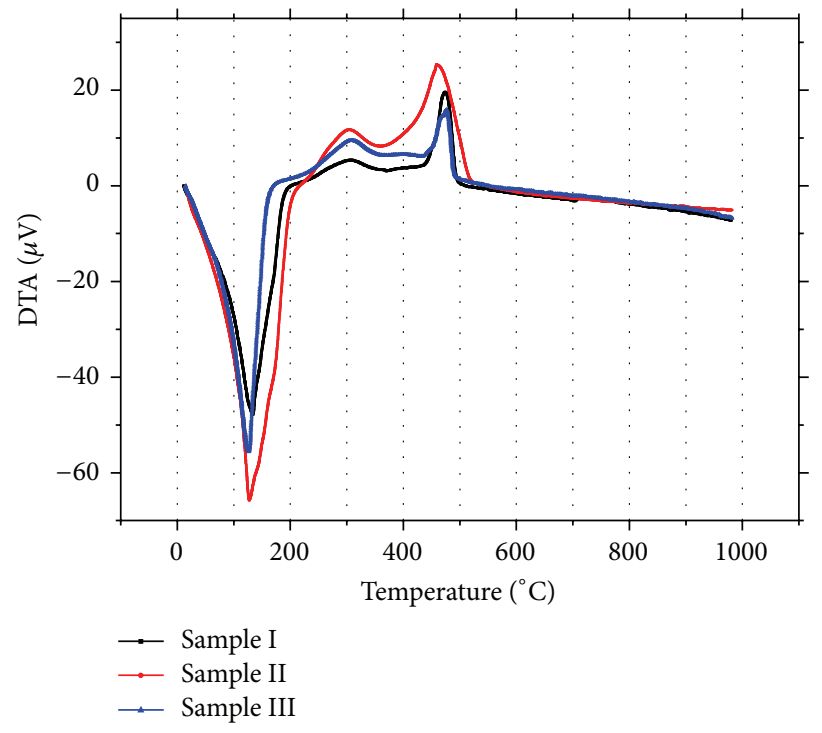

(b) The curve of DTA

FIGURE 11: The curve of the thermal effect at 28th day of the fermentation. 
was lower than the outside, resulting in the fact that the dehydration of the free water firstly happened in the outside wall then in the inside wall of the pore. After 28 days of the anaerobic fermentation, since the organic on the surface of the inside and outside walls of the pore and on the hole of the pore was degraded, the wall became thinner and the hole became larger. Therefore, the heat conductivity efficiency was significantly improved and the fluctuation of the endothermic valley disappeared.

From the DTA curves, it can be drawn that the peak value at $480^{\circ} \mathrm{C}$ of the exothermal peak at 14 th day was $1.81-$ $14.50 \mu \mathrm{V}$, larger than that of the 28th day. And the peak value of the exothermal peak was in proportion to the exothermal amount, indicating that the content of the organic in the sewage sludge was significantly decreased with the continuing of the fermentation. Thus, the heat produced in the burning of the organic at $480^{\circ} \mathrm{C}$ became less and the peak value of the exothermal peak was smaller too. Since the anaerobic fermentation hardly had effect on the moisture content of the sewage sludge, the time of the fermentation only had little effect on the value of the endothermic valley of the same sample.

In addition, the mass loss of sample II was larger than that of samples I and III, in the same reaction time. The minimum value of the endothermic valley and the peak value of the exothermal peak of sample II were also larger. The original moisture content of sample II was relatively higher and the microorganism took in the water when the degradation of organics happened in the anaerobic fermentation. Thus, the moisture loss in the heating procedure was more obvious. Moreover, the outside environment of sample II was more suitable for the anaerobic fermentation; the number and the activity of the microorganisms of sample II were both larger than those of samples I and III. Therefore, the endothermic valley and the exothermal peak of sample II were bigger and more significant.

\section{Conclusions}

To study the releasing rules of the pollutant, microstructure, the phase deformation, and the component of the sewage sludge in the anaerobic fermentation and to find theoretical foundation for the use and harmless disposal of the sewage sludge, the pollutant releasing test, the static nitrogen adsorption test, and the TG-DTA test were performed to determine the concentration of pollutant, pore structure, and properties in the thermal effect of the sewage sludge with differently original $\mathrm{pH}$ value on the anaerobic fermentation. From the test results, the conclusions can be drawn as follows.

(1) The $\mathrm{pH}$ value of samples declined firstly and then increased with the continual of the fermentation. The difference values between the original $\mathrm{pH}$ value and the final $\mathrm{pH}$ value of samples I and III were both smaller than $2 \%$, while the difference value of sample II was $4.5 \%$. The contents of organic and the $\mathrm{BOD}_{5}$ both gradually decreased with the continual of the fermentation, and the decreasing rate during 2-15 days of the fermentation was relatively high. At the end of the test, the content of the organic and the $\mathrm{BOD}_{5}$ of sample
II declined most which were $37.3 \%$ and $53.6 \%$, respectively, and they were still slowly decreasing.

(2) The adsorption isotherms of sewage sludge in the anaerobic fermentation belonged to kind IV, and there existed a $\mathrm{H}_{3}$ kind hysteresis loop in the curve. The maximum amount of adsorption was $69.24 \mathrm{~cm}^{3} / \mathrm{g}$. The proportion of pore smaller than $6 \mathrm{~nm}$ was large and the curve of total pore volume was similar to a line. The maximum values of total pore volume were between 0.126 and $0.178 \mathrm{~cm}^{3} / \mathrm{g}$. With the increasing of the time of the anaerobic fermentation, the average pore size of sample particles increased 16.0-19.8\%, and the total pore volume also slightly increased. In the same time of the fermentation, the specific surface area of sample II was smaller and the average pore size was larger than that of samples I and III.

(3) When the temperature was between 0 and $200^{\circ} \mathrm{C}$, the mass loss of sewage sludge samples was 32.9-39.1\% and there existed significant endothermic valley since the dehydration of free water. When the temperature was between 200 and $600^{\circ} \mathrm{C}$, the mass of sewage sludge decreased a little and there existed two exothermal peaks because of the oxidative cleavage and the burning of organics. When the temperature was higher than $600^{\circ} \mathrm{C}$, the TG and DTA curves were more smoothly. In the curves of the samples at 14th day of fermentation, there appeared an obvious fluctuation at the endothermic valley and the peak value of the exothermal peak was comparatively large. At the same time of the heating procedure, the mass loss and endothermic valley and the exothermal peak of sample II were all larger than those of samples I and III.

\section{Conflict of Interests}

The authors declare that there is no conflict of interests regarding the publication of this paper.

\section{Acknowledgments}

The authors would like to express their great appreciation for funding provided by the National Natural Science Foundation of China (51474168) and Nature Science Foundation of Hubei Province (2014CFB889).

\section{References}

[1] A. Katsoyiannis, A. Zouboulis, and C. Samara, "Persistent organic pollutants (POPs) in the conventional activated sludge treatment process: model predictions against experimental values," Chemosphere, vol. 65, no. 9, pp. 1634-1641, 2006.

[2] S. J. Hang, X. D. Liu, and P. Liang, "Misunderstanding of sludge disposal and treatment and control strategy," China Water \& Wastewater, vol. 20, no. 12, pp. 89-92, 2004.

[3] Y. H. Cao and C. Q. Yin, "Engineering properties and landfill of stabilized sludge," Applied Mechanics and Materials, vol. 295298, pp. 1751-1754, 2013.

[4] L. L. Qian, S. Z. Wang, and X. Y. Tang, "Experimental study on hydrothermal treatment of municipal sewage sludge," Applied Mechanics and Materials, vol. 448-453, pp. 693-698, 2014. 
[5] X. X. Han, M. T. Niu, X. M. Jiang, and J. Liu, "Combustion characteristics of sewage sludge in a fluidized bed," Industrial and Engineering Chemistry Research, vol. 51, no. 32, pp. 1056510570, 2012.

[6] P. Chen, L. Zhan, and W. Wilson, "Experimental investigation on shear strength and permeability of a deeply dewatered sewage sludge for use in landfill covers," Environmental Earth Sciences, vol. 71, no. 10, pp. 4593-4602, 2014.

[7] N. Wei, "Sewage sludge solidification by slag-based modifier for landfill cover," Advanced Materials Research, vol. 113-116, pp. 425-428, 2010.

[8] A. Biasin, M. Della Zassa, M. Zerlottin, D. Refosco, R. Bertani, and P. Canu, "On the understanding and control of the spontaneous heating of dried tannery wastewater sludge," Waste Management, vol. 34, no. 4, pp. 817-824, 2014.

[9] A. G. Vlyssides and P. K. Karlis, "Thermal-alkaline solubilization of waste activated sludge as a pre-treatment stage for anaerobic digestion," Bioresource Technology, vol. 91, no. 2, pp. 201-206, 2004.

[10] Y. Chen, A. A. Randall, and T. McCue, "The efficiency of enhanced biological phosphorus removal from real wastewater affected by different ratios of acetic to propionic acid," Water Research, vol. 38, no. 1, pp. 27-36, 2004.

[11] S. Wang, J. Li, S. Chang, and Z. Wang, "Effect of pretreatment temperature on hydrogen production by fermentation of anaerobic granular sludge," CIESC Journal, vol. 62, no. 3, pp. 811-815, 2011.

[12] J. Z. Fang, Y. Y. Li, and C. F. Xu, "Error analysis of single point BET method with ASAP2010," China Measurement Technology, vol. 32, no. 5, pp. 42-45, 2006.

[13] M. Seggiani, M. Puccini, G. Raggio, and S. Vitolo, "Effect of sewage sludge content on gas quality and solid residues produced by cogasification in an updraft gasifier," Waste Management, vol. 32, no. 10, pp. 1826-1834, 2012.

[14] Y. N. Chun, S. C. Kim, and K. Yoshikawa, "System development and analysis for producing high quality gas and activated sludge char," Journal of Mechanical Science and Technology, vol. 26, no. 1, pp. 241-250, 2012.

[15] T. T. Liu and J. Y. Cao, "Study on the isolation and growth condition of methanogen," Chinese Journal of Heilongjiang Hydraulic Engineering College, vol. 34, no. 4, pp. 120-122, 2007.

[16] B. D. Zdravkov, J. J. Čermák, M. Šefara, and J. Janků, "Pore classification in the characterization of porous materials: a perspective," Central European Journal of Chemistry, vol. 5, no. 2, pp. 385-395, 2007. 

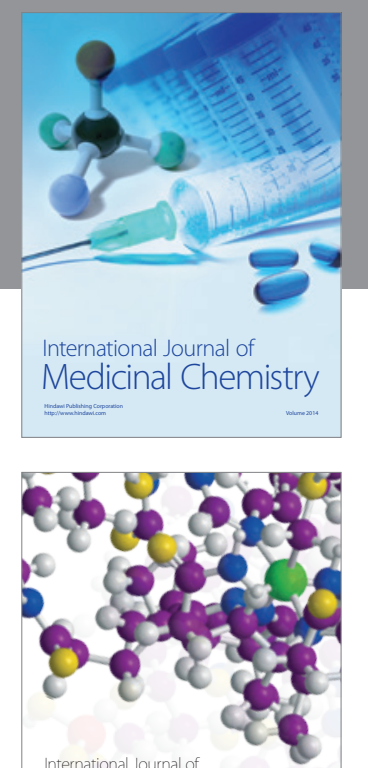

\section{Carbohydrate} Chemistry

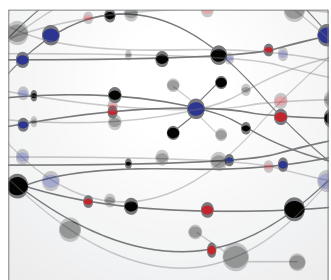

The Scientific World Journal
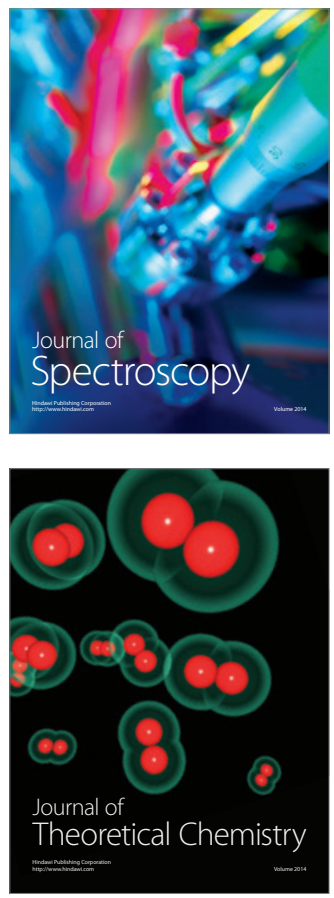
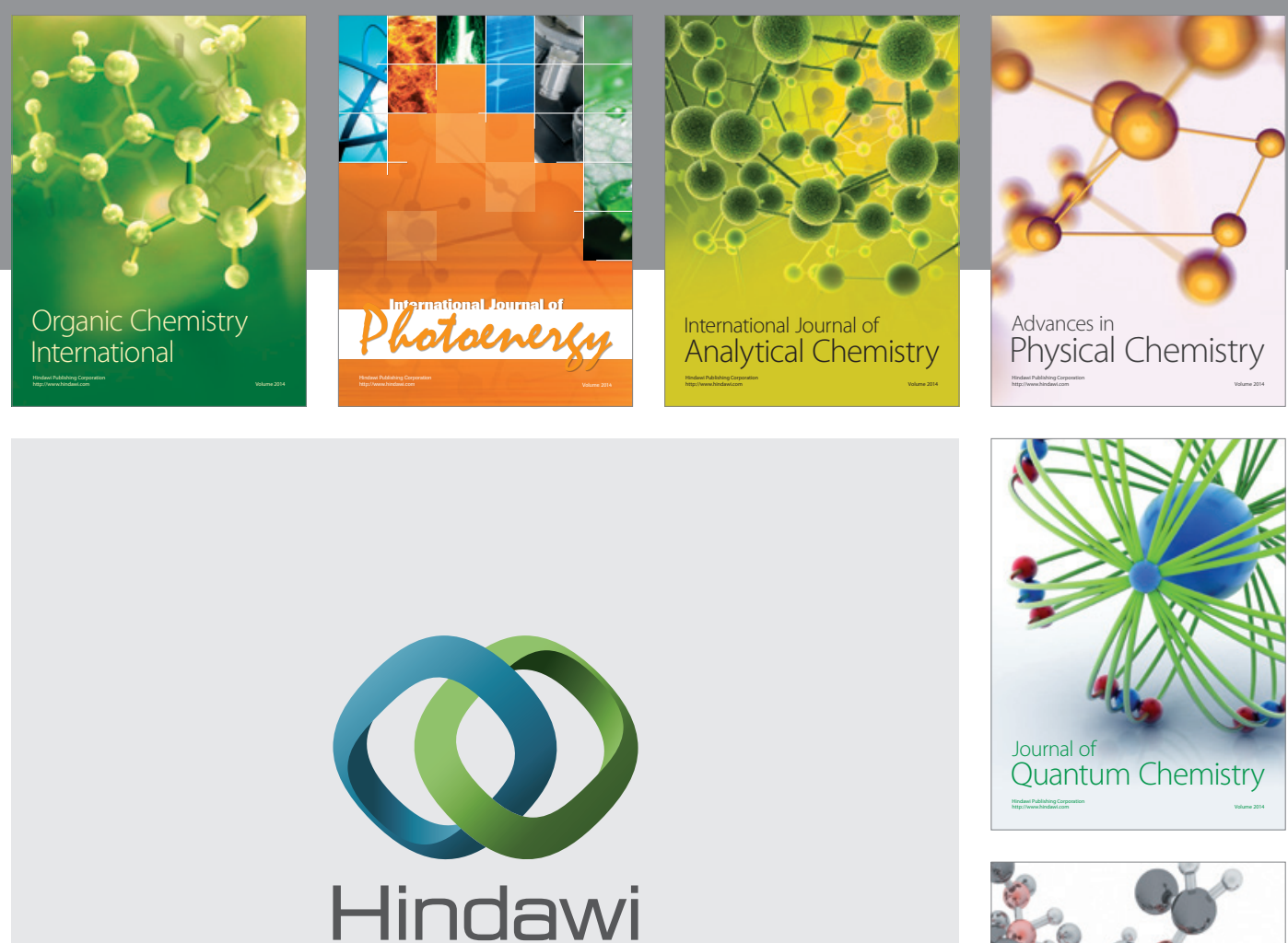

Submit your manuscripts at

http://www.hindawi.com

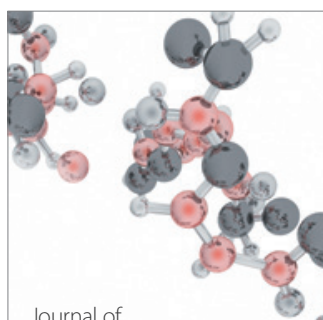

Analytical Methods

in Chemistry

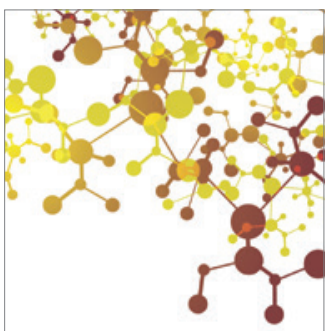

Journal of

Applied Chemistry

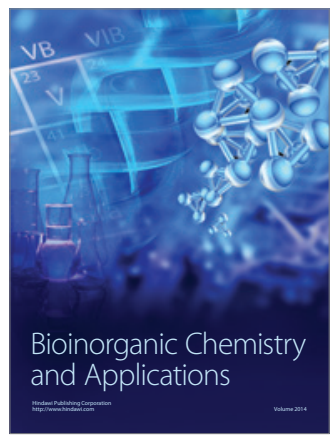

Inorganic Chemistry
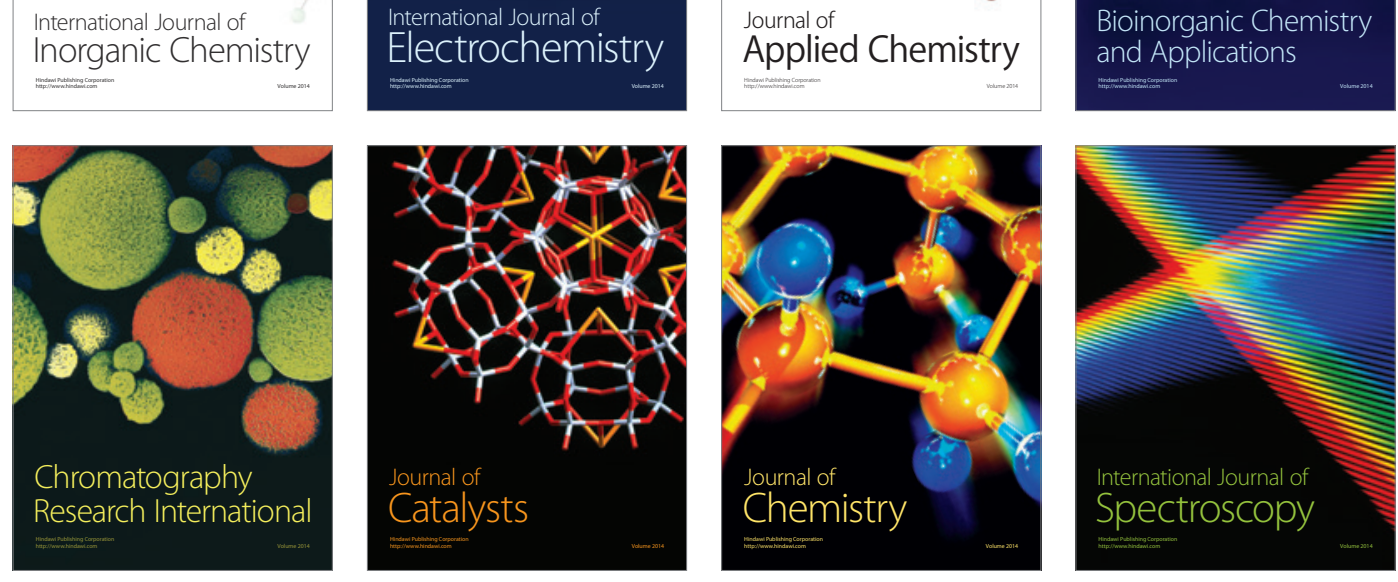